\title{
Eurocentrismo, H istória e História da África ${ }^{1}$
}

\author{
Muryatan Sartana Barbosa²
}

\begin{abstract}
Resumo: Formada em um viés eurocêntrico, a História, enquanto disciplina acadêmica passou por diversas adaptações e transformações, visando se construir como uma área do saber universalista e científica. Apesar de ainda estar longe deste objetivo, é perceptível que ela registrou avanços nesta direção, sobretudo, na segunda metade do século XX. Aqui, destacar-se-á, resumidamente, como os historiadores da África vêm colaborando com tal empreendimento, na busca de um olhar renovado sobre o continente e seus povos.
\end{abstract}

Palavras-chave: História, História da África, Eurocentrismo.

Summary: History as an academical matter was developed under an eurocentric bias. It has however gone through changes and adaptations to become scientific and universalised. While still far from this goal, it has advanced to this frame particularley in tree second half of the $20^{\text {th }}$ century. In the following digression it will be shortly detached how the present-day historians of Africa are contributing to this Task, through the search of a new glance on that continent and its peoples.

Key-words: History, History of Africa, Eurocentrism.

\section{Eurocentrismo e H istónia}

Existe hoje certo consenso nos debates acadêmicos sobre a necessidade de uma discussão das concepções euroêntricas dominantes na ciência social moderna e contemporânea ${ }^{3}$. Todavia, apesar de sua amplitude, tal debate tornou-se fato recentemente. Basta lembrar que as contribuições pioneiras sobre o assunto datam da década de 1950 e 60, como aquelas dos sociólogos Guerreiro Ramos (Redurãosocidóġca, 1958) e Abdel-Malek (A dalética soial, 1972). Foi apenas com o celebre livro de Edward Said, Orietalismo(1978), que o tema tornou-se assunto candente no debate acadêmico internacional.

Existem diversas formas de caracterizar o chamado eurocentrismo. Por vezes, ele é visto como mero fenômeno etnocêntrico, comum aos povos em outras épocas históricas. Mas para a maioria dos autores que tratam atualmente da questão, o eurocentrismo deveria ser caracterizado, diferentemente, como um etnocentrismo singular, entendido como uma ideologia, paradigma e/ ou discurso.

A distinção entre tais termos é mais uma questão de ênfase interpretativa, do que discordância conceitual. Os autores que o tratam como discuso visam analisálo, geralmente, em sua manifestação no senso comum, nos meios de comunicação de massa, nas instituições, etc. (Shohat \& Stam, 1997). Por outro lado, os autores que preferem

${ }^{1}$ Agradeço as professoras Marina de Mello e Souza (D H-USP) e Patrícia Santos Schermann (D H-UNIFE SP) pela leitura de versão anterior deste artigo.

${ }_{2}^{2}$ Professor universitário, Mestre em Sociologia e doutorando em História Social pela FFLCH-USP. Contatos: murybarbosa@ hotmail.com/murybarbosa@usp.br.

${ }^{3}$ Ver, por exemplo, o relatório da Comissão Calouste Gulbenkian, em 1996, sobre a reestruturação das ciências sociais. Entre outros, publicado em WALLERSTEIN, Immanuel et al. Para abrir as ciêmias soiais São Paulo: Cortez, 1996. 
enfatizá-lo como ideologia e/ ou paradigma, tendem a focar, em seus estudos, o caráter eurocêntrico do pensamento erudito europeu-ocidental, em sua filosofia, teoria social, etc. (Young, 1990; Dussel, 1993).

Para todos, entretanto, o eurocentrismo deve ser entendido como uma forma de etnocentrismo singular, qualitativamente diferente de outras formas históricas. Isso porque ele é a expressão de uma dominação objetiva dos povos europeus ocidentais no mundo. Neste sentido, Samir Amin (1994), por exemplo, definiu o eurocentrismo como a crença generalizada de que o modelo de desenvolvimento europeu-ocidental seja uma fatalidade (desejável) para todas as sociedades e nações. Segundo este autor, uma ideologia, cuja genealogia deveria ser buscada no Renascimento, remontando à gênese do capitalismo como sistema mundial, ou, em suas palavras, como modo de produção realmente existente.

Partindo desta definição de Amin, mas nem sempre em concordância com ela, outros autores, como Anibal Quijano (2000), tem preferido conceituar o eurocentrismo como um paradigma. Isso porque sua característica singular seria a de se reproduzir como uma estrutura mental, consciente ou não, que serve para classificar o mundo. E, portanto, poder abondá-lo.

Entender-se-á, neste texto, tais interpretações como complementares. Assim, pois, o eurocentrismo é aqui pensado como ideologia e paradigma, cujo cerne é uma estrutura mental de caráter provinciano, fundada na crença da superionidade do modo de vida e do desenvolvimento europeu-ocidental.

Assim entendido, é hoje perceptível o quanto este eurocentrismo esteve presente nos textos clássicos que fundaram a historiografia moderna no Iluminismo, deturpando a visão dos europeus acerca dos demais povos do mundo. Estes eram vistos, então, na melhor das hipóteses, como crianças a serem educadas pelas luzes da Razão. Existe uma literatura recente que analisa esta visão em autores clássioos como Descartes (Quijano, 2000), Kant (Eze, 1997), Hegel (Dussel, 1993) e outros.

O mesmo olhar pode ser identifcado no pensamento social euppeu do novecentos, de forma mais diversificada. Existe uma tendência eurocêntrica recorrente, por exemplo, nas Filosofias da História dos séculos XVIII e XIX, a partir de autores clássicos como Voltaire, Vico, Condorcet, Hegel, Marx e Engels. É certo que existe uma heterogeneidade evidente no pensamento de tais autores. Todaria, o que os une enquanto principais fundadores da Teoria da História, são suas tentativas de, a partir da Filosofia, construir interpretações evolutivas das sociedades humanas, baseadas no progresso da histónia européia-ocidental. 
Além das Filosofias da História, teorias sociais do século XIX, como 0 evolucionismo de Spencer e o positivismo de Comte, podem ser considerados casos extremos deste provincialismo europeu, auto-declarado como universalista. Nestas perspectivas francamente eurocêntricas, as sociedades e os povos "pré-modernos" ou "arcaicos" deveriam ser estudados como estágios de um caminho civilizacional único, cujo ápice seria a Europa O cidental. Assim, pois, o passado destas sociedades deveria ser um exemplo inicial deste processo evolutivo.

Em todos os casos citados, se reproduz, portanto, a crença na excepcionalidade européia, definida de diversas formas. Desde uma compreensão econômico-social (o capitalismo); culturalista (modernidade, cultura greco-romana); religiosa (judaico-cristã); racial ("branca"), etc. Tratłse, pois, em ultima instância, de um problema ontológico recorrente, ainda não examinado como merece ${ }^{4}$.

Esta visão eurocêntrica de mundo condiciona o nascimento disciplinar da Historia como pode-se observar, por exemplo, em obras de dois "pais" da disciplina: Michelet e Ranke. Cada um a seu modo, tais autores buscaram reconstruir a história de sua nação como representante máxima da "especificidade" européia; seja por sua face modema, contratualista (Michelet); seja por sua face romântica, de origem místico-religiosa (Ranke) (Fontana, 1998). Refaz-se, assim, na História, a associação entre os nascentes EstadosNação da Europa $O$ cidental e a institucionalização das ciências humanas, levando a uma reorientação da ideologia eurocêntrica em categorias como "povo" e "nação", marcando, inclusive, distinções entre os próprios pensadores europeus.

Mas o que ocorre ao historiador, ou filósofo social, quando, olhando para o passado de outros povos e civilizações, não se pudesse encontrar neles a genealogia da modemidade européia-ocidental? Trata-se de uma questão pertinente. Hegel, por exemplo, foi peremptório neste ponto ao falar sobre o passado da África, que aqui interessa ressaltar. Dizia o filósofo alemão que, ao se analisar a história da África, não se poderia ali encontrar progressos e movimentos histónicos. Sua conhecida conclusão, pois, considerou que a África não faria parte da "história do mundo".

Por mais estranheza que esta assertiva traga hoje para uma visão politicamente correta da ciência, ela toca en premissas desconcertantes para um pensamento

${ }^{4}$ Referindo-se à teoria de Max Weber sobre a modernidade capitalista, Renato Ortiz (2000) coloca adequadamente 0 problema. Quando aquele se pergunta: porque 0 capitalismo nasce no Ocidente? A resposta pode ou não ser pertinente, assim como pode ou não ser tida como cientifica. Mas, de fato, ao ser colocada, tal pergunta está intrinsecamente viciada, porque, como observa Ortiz, a idéia de Ocidente pressupõe uma oposição binária, falsa, à de O riente. Como se estas duas categorias representassem categorias de fenômenos heuristicamente opostos, quando, em verdade, são construções sociais, cuja genealogia, aliás, foi recentemente decifrada por autores como Edward Said (1990) e Fernando Coronil (1999). 
historiográfico de viés evolucionista e/ ou positivista. Afinal, além da aparente falta de grandes "progressos" ou "movimentos históricos", a realização de uma história da África engendra uma dificuldade também em relação à sua conhecida falta de fontes, sobretudo escritas, para a reconstrução histórica. Este é um dilema que, para existir como sub-área do conhecimento historiográfico, a História da África teve que responder.

\section{Historiografia contemporânea e História da África}

Apesar do que foi até aqui dito, seria um erro supor que, por serem eivadas de eurocentrismo, a filosofia e a teoria social européia dos séculos XVIII e XIX em nada teriam contribuído para 0 desvelamento de realidades históricas não européias. Em verdade, pouco se escreveu e analisou, até o início do século XX, acerca da história de outros povos e civilizações. Há, entretanto, uma questão importante. 0 fato é que, ao se expressarem como universalistas sendo, em verdade, provincialistas, os europeus ajudaram a criar o instrumental teórico pelo qual os demais povos poderiam, tendencialmente, re significar a imagem que aqueles faziam de si.

Isso é perceptível, por exemplo, em uma herança crítica que, indiretamente, trouxe mais elementos para esta inversão dialética da teoria social européia. Trata-se do historismo (ou historicismo), cuja origem, na filosofia, é geralmente tribuída a Herder, pensador alemão do século XVIII. Aqui \& definirá o historismo como a herança crítica interpretativa baseada na premissa de que os fatores de compreensão de uma sociedade assim como de um povo, cultura, etc - deveriam ser entendidos a partir dos seus fatores internos, e não extemos (Edgar \& Sedgwick: 155-56). Assim definido, o historismo, desde Herder com suas investigações sobre a essência espiritual dos povos e sua evolução, pode ser observado, com suas nuances, em uma série de tradições modemas e contemporâneas, como, por exemplo: (a) as contradições intemas como motor da dialética (Hegel, Marx e Engels); (b) a interpretação compreensiva dos sentidos e condutas humanas (Dilthey, Weber, Sombart e outros).

Além de sua importância para outras áreas do pensamento, essa tradição historista teve também uma influência marcante na renovação historiográfica do inicio do século $\mathrm{XX}^{5}$. Aí ela ajudou a justificar um distanciamento gradual, mas decisivo, desta em relação à historiografia tradicional de cunho político-diplomático, dominante no século XIX. Podese observar tal ensejo na obra de diversos historiadores da passagem dos séculos XIX e

${ }^{5}$ Evidentemente, o historismo não é a única tradição crítica importante que influenciou na renovação da historiografia no início do século XX. Dado o interesse deste artigo e, por economia de espaço, destacou-se tal herança, mas, como é sabido, existem outras teorias que contribuíram com tal fato. 
XX, como Fustel de Coulanges, Gustav Schmoller, Karl Lamprecht, James Robinson, Henri Berr e outros.

Todavia, a ruptura com esta História Tradicional só foi consolidada a partir dos anos 1930, com as contribuições clássicas da Escola dos Annales. Em texto conhecido, Peter Burke (1991) definiu esta "revolução" dos Annales na historiografia em três pontos centrais: (a) a interdisciplinaridade; (b) a perspectiva totalizante; (c) a históia "problematizada". Em Marc Bloch, Apdogia à Histara, Lucien Febvre, Conbates pda Histaia e Fernand Braudel, Histria edêniassoiais, vê-se 0 cerne desta nova proposta historiográfica que, com a ampliação e especidização do campo acadêmico, foi reinterpretada por historiadores de outros países e correntes de pensamento.

Hoje são perceptíveis as razões teóricas que possibilitaram que esta renovação historiográfica tenha se difundido rapidamente pelo mundo, sob a tutela dos Annales. Tal difusão, todavia, decorreu também de fatores extraacadêmicos. Entre os vários que se poderia citar, cabe aqui lembrar a importância simbólica que as duas Guerras Mundiais tiveram para a derrocada do otimismo europeu acerca de sua própria sociedade.

A forma como este fato iria impactar no pensamento europeu deu-se variada. Para alguns, a tragédia da Guerra comprovaria a decadência da cultura ocidental de época, que teria perdido sua "verdadeira" força espiritual, cuja origem foi atribuída a fontes diversas: cristã, medieval, greco-romana, helenística, etc. Para outros, mais relativistas, haveria de se repensar o papel civilizatório do Ocidente no mundo; ou, quiçá, os próprios vabres ocidentais. Seja como for, a História assim como a Antropologia Cultural e a Etnologia surgiriam renovadas no pós-guerra. Para o desespero de Marc Bloch, ela tornar-se-á, então, um belo refúgio do presente...

Enquanto expressão da historiografia contemporânea, do Pós-guerra (2ª Guerra Mundial), a História da África é resultante destes dois fatores: (a) a renovação crítica das Ciências Sociais, em particular, na historiografia; (b) o crescente relativismo europeu diante de seus próprios valores. Este fato faz com que muitos dos aanços ali conquistados possam ser vistos como pertenœentes a uma renovação historiográfica maior, da primeira metade do século XX. O nascimento disciplinar da História da África, sobretudo na França e na Inglaterra, foi uma consẹuiência desta ampliação paradigmática da História tradicional.

Como observa Costa e Silva (1996), isto é perceptível, por exemplo, nos primeiros estudos europeus sobre a África no pós-guerra, quando surgiram importantes publicações especializadas sobre a História da África, como o TheJaumal African Histary, na Inglaterra, e 
o Bullein del'Insitut Frangais del'AfiqueNaie na França. Para além da academia, três livros dos anos 1950 e 60 trazem ao público um importante conhecimento introdutório sobre 0 assunto. São eles: (a) A velh Áfica redescobata (1959), de Basil Davidson; (b) Históia dos pous da África nega (1960), de Robert Corvenier; (c) Brevehistóia da África, de R. Oliver e J. Fage (1962); (d) Históia da África Nega(1961), de Jean-Suret Canale.

Em paralelo a este crescimento do interesse europeu sobre o continente africano, se forma, desde os anos 1950, uma historiografia sobre a África realizada pelos próprios africanos. Trata-se, inicialmente, de uma literatura que fazia eco com as primeiras lutas de libertação nacional na África. Neste contexto, tratavase de construir uma História que pudesse servir como instrumento de luta ideológica e política contra o inimigo colonialista.

O primeiro grande historiador africano desta geração dos anos 1950 e 1960 foi 0 senegalês Cheikh Anta Diop, criador do Afro-centrismo. Em livros conhecidos como Naçães negas e ailtura (1955) e Anteicicade das divilizaçôes aficanas (1967; traduzido para 0 inglês como As crigns aficanas da đivilizaçãa 1973), Diop retomou, de forma transformada, uma tese do século XIX, de que o Egito fôra uma civilização negróide; tida como origem cultural do mundo helenístico (por consequiência, greco-romano) e das sociedades africanas.

Com esta tese, Diop perseguia um duplo objetivo. Primeiro, defender a africanidade do Egito Faraônico e, portanto, do mundo mediterrânico antigo, de onde teria surgido a maior parte das civilizações indo-européias. Em segundo lugar, apoar o princípio da unidade cultural africana. Isso porque, de acordo com Diop, os povos do continente africano teriam, em última instância, a mesma origem egípcia (kentíikớ). Esta possuiria as seguintes características primordiais: estrutura matriarcal, a expressão dionisíaca da vida, 0 idealismo religioso, o coletivismo e o otimismo.

Como observa o historiador Boubacar Barry (2000), entre fins dos anos 1950 e início dos 1960, surgiram também outras duas importantes obras neste período inicial dos estudos africanos sobre a África: Camparhas dbSenegal (1958), de Abdoulaye Ly, e, Sudata ou oéicomandinga, de Djibril Tamsir Niane (1960).

No primeiro livro citado, o historiador Abdoulaye Ly retoma análises pioneiras de Eric Williams (Capitalismo e cravicắ 1944), para analisar o papel central que a África e os africanos tiveram para a formação do capitalismo e do mundo moderno. Sua intenção era

\footnotetext{
${ }^{6}$ Kenćticoé um termo utilizado por Diop, e pela maioria dos afrocentristas contemporâneos, para se referir à pertença negra dos egípcios antigos. Segundo estes, Knt, geralmente transcrito como Kenit ou Kent, era um dos nomes pelos quais os egípcios denominavam a sim mesmos e a sua nação. Ela significaria, segundo estes, "Os pretos" e "A terra dos pretos". Isso é considerado importante por estes porque demonstraria que os antigos egípcios tinham consciência de sua negritude (Farias, 2003: 330).
} 
construir uma inversão à narrativa colonial ainda reinante, que tendia a ver os africanos em seu suposto estado a-histórico.

Em 1960, o historiador Djibril Tamsir Niane, publica também outro importante trabalho acerca da História africana: Sundjata au o épico mandinga Trata-se de um dos primeiros ensaios a utilizar fartamente a história oral, e, conseqüentemente, a figura dos "tradicionalistas" africanos ${ }^{7}$, como fonte de trabalho historiográfico; embora a origem deste intento possa ser encontrada em obras anteriores, como, por exemplo, Breehistóia doBenim (1934), de J. U. Egharevba ${ }^{8}$.

Como observa Barry (2000: 24), esta obra de Niani, assim como o livro metodológico de Jean Vansina sobre a história oral, A tradição oral (1961, revisto em 1985), tomaram-se obras de referência para a geração de historiadores africanos da África que irá surgir a partir da década de 1960. D esde então, a história oral passa a ser vista como um instrumental essencial para a construção de uma História da África científica e descolonizada. Algo defendido, entre outros, pelo influente líder pan-africanista Kwane N 'Krumah, no fechamento do Primeiro Congresso Internacional de Africanistas, em 1961, em Acra (Curtin, 1980: 79).

Os anos 1950 e 1960 são também o período áureo da Sociedade Africana de Cultura e de sua revista, PrésenceAfricaine, principal órgão de divulgação do pensamento da intelectualidade africana e afro-descendente do Pósguerra. Retoma-se, ali, um elo diaspórico negro, em que os intelectuais africanos e afro-descendentes se colocam como co-partícipes de uma mesma comunidade de interesses, na luta contra o racismo e o colonialismo. São vários os termos para se referir a esta unidade: raça, etnia, povo, cultura, população, etc. Seja qual for o termo, se fortalece um sentido comum de luta, dentro de um universo simbólico contemporâneo. Os dois congressos de Escritos e Artistas Negros à época, em Paris (1956) e Roma (1958), são uma concretização deste ideal.

No mesmo período, livros como Os condenadbs da Tera (1961), de Frantz Fanon, e Rerato do colonizador preceddo palo retrato do colarizadb (1957), de Albert Memmi, tornam-se

7 Utiliza-se este termo no sentido que lhe dá Amadou Hampaté Bâ (1980: 187ss). Para o autor, os "tradicionalistas" são os homens que seriam os grandes depositários da herança oral africana. Nas línguas africanas, costumam ser definidos como os "conhecedores"; seja por serem iniciados (e iniciadores) em um determinado ramo especifico (tecelaria, metalurgia, etc), seja por serem portadores de um conhecimento total da tradição local. Segundo Bâ, o ultimo caso é o mais comum, pois o conhecedor geralmente é tido por um "sabedor da vida". Estes poderiam ser identificados por vários termos, conforme a região: doma, soma, silantigui, gando, tchiorinke, etc. 0 conhecedor seria, assim, distinto da figura do griot africano (ou diali), mais comum na literatura sobre o tema. Isto porque, para Bâ, o primeiro é, sobretudo, um portador da "verdade"; enquanto que o segundo seria, essencialmente, um animador público, sendo-lhe permitida total liberdade de expressão.

${ }^{8}$ Antes deste, cronistas muçulmanos, administradores coloniais e antropólogos como Henri Gaden, Maurice Delafosse e Gilbert Vleillard, tiveram foram fundamentais no registro da história oral de diferentes regiões do continente africano. Não são, entretanto, discursos históricos, como os aqui comentados. 
obras célebres dos movimentos de descolonização, seja na África, seja na América, contra 0 colonialismo intemo. Aí, o sentimento diaspórico ganha, sem dúvida, contomos mais radicais.

No que se refere ao trabalho historiográfico, entretanto, é hoje perceptível o quanto as dificuldades intrínsecas à libertação nacional dos países africanos trouxeram para a consolidação de um campo acadêmico no continente, nos anos 1950 e 1960. Nos países colonizados, era ainda predominante uma etnologia de escasso valor científico, advinda das necessidades de administração colonial. Nos países já independentes, como Libéria, Argélia, Sudão, Marrocos, Tunísia, Nigéia e outros, as condições de institucionalização e estruturação do campo acadêmico eram dişndiosas e lentas. Ademais, com a independência conquistada, muitos dos intelectuais africanos que poderiam auxiliar nesta tarefa passaram a ocupar altos cargos na administração estatal, necessários à construção ou reconstrução de suas nações.

Essa incipiência do campo historiográfico na África, nos anos 1950 e 1960, fez com que a nascente historiografia acadêmica estivesse ainda vinculada à herança historiográfica européia. A exceção de intelectuais pioneiros, como, por exemplo, Anta Diop, Niani e Abdoulaye Ly, a História disciplinar no continente era ainda dependente das instituições acadêmicas estrangeiras, sobretudo européias, estadunidenses e soviéticas.

No caso de França e Inglaterra sobretudo, esta dependência era especialmente paradoxal, por estes terem sido metrópoles de vários países africanos nascentes. É que justamente aí se formaram, nos anos 1950 e 1960, importantes áreas disciplinares de História da África. No primeiro, por exemplo, se destacaram a Universidade de Londres e a Escola de Estudos O rientais e Africanos; e, no segundo, a Sorbonne, o Centro de Estudos Africanos e na École Pratique des Hautes Études.

Também nos EUA e União Soviética ocorreu um processo parecido de ampliação dos estudos africanos. No primeiro, a partir dos anos 1960, viu-se uma luta acirrada, em particular, dos afro-americanos, pela inclusão de matérias relativas à África nos currículos de História. Tal desejo tornou-se realidade e, entre 1960 e 1972, se formaram mais de 300 doutores em África no país, em instituições como a Universidade de Howard, em Yale e na Associação de Estudos Africanos. Na URSS, nos 1960, a luta anti-colonial e a aproximação de lideres africanos com o maxismo, impulsionaram a difusão de áreas disciplinares dedicados a África, em especial, no Instituto Etnográfico de Leningrado e na Universidade Patrice Lumumba. Não se tem, salvo melhor juízo, uma quantificação do número de 
estudantes africanos que foram estudar nestas instituições nos 1950 e 1960. Sabese, entretanto, que são centenas (Curtin, 1980: 84ss).

Por outro lado, na mesma época, historiadores europeus e estadunidenses foram ensinar História da África na África, se tornando especialistas ou aperfeiçoando-se na temática. Este foi o caso, por exemplo, de J. D. Fage em Gana; J. D. Hargreaves, em Serra Leoa; C. Wrigley e C. Ehrlich, na Nigéria; J. Vansina, no Congo e em Ruanda, R. Mauny e Y. Person no Senegal (Curtin, 1980: 85).

Em parte por esta participação, se formaram, ao longo das décadas de 1950 e 1960, os primeiros centros universitários no continente que davam especial interesse à História na África em seus currículos, como a Universidade de Dakar (Senegal), o Gordon College de Cartum (Costa do Ouro, posteriormente Gana), o Makerere College de Kampala (Uganda), a Universidade de Ibadan (Nigéria), a Universidade de Lovanium (Congo, posteriormente Zaire), a Universidade de Dar-Es-Salam (Tanzânia) e a Universidade de Nairobi (Q uênia). Em 1956, foi nomeado o primeiro diretor africano de um Departamento de História, o professor Kenneth Onwuka Dike, em Ibadan (Fage, 1980: 58).

É certo que a formação intelectual dos jovens estudantes africanos nestas e outras universidades fora da África, assim como o ensino dirigido por professores europeus e estadunidenses no próprio continente, foi um fato condicionante do tipo de prática profissional que se estabeleceu entre os historiadores nativos, a partir da década de 1970. Todavia, apesar deste fato, o intento de descolonizar a História para projetar uma "verdadeira" História da África, segue sendo, aparentemente, um objetivo desta geração de historiadores africanos. Este também era um desejo confesso de muitos intelectuais estrangeiros que se dedicaram ao tema a partir da década de 1960. Os movimentos de Independência, neste sentido, foram, sem dúvida, os motivadores para a ampliação e difusão dos estudos africanos em todo o mundo.

A pesar desta proximidade relativa de objetivos, os historiadores africanos, ao longo da década de 1960 e 70, organizaram tentativas de construir um espaço próprio de discussão sobre a temática da descolonização da História africana. Segundo Barry (2000: 52ss), este intento marca a relização de encontros regulares, como o Congresso de Africanistas de 1961, o Congresso Internacional sobre a História da África, em 1965, na Tanzânia (também conhecido como o Encontro de Dar-Es-Salam), e 0 de Yaundé, em Camarões, em 1975. Ademais, œ organizou a primeira Associção Pan-Africana de Historiadores, em 1972. Nestes, houve uma aproximação das propostas pan-africanistas com o marxismo, uma tendência corrente à época de marcos da luta política africana e 
afro-descendentes como Kwane N'Krumah e W. E. Du Bois. Todavia, a divisão entre língua, em especial, entre os historiadores de língua inglesa e francesa, parece ter sido um constante problema para a organização de encontros inter-regionais entre historiadores africanos à época.

O mesmo processo ocorre nas universidades africanas. Conforme foi aumentando o número de professores locais nestas instituições, ao longo da década de 1960 e 1970, aumentou também o interesse na formação de uma nova História, descolonizada.

Desde então, independente do fato de ser realizada por africanos ou estrangeiros, esta difusão de interesse pela História da África, promoveu grande quantidade de livros essenciais para o aumento do conhecimento acerca da temática, a partir dos anos 1970.

Seria ilusório tentar citar todos os autores e livros que, a partir desta época, participaram da ampliação deste campo do conhecimento. Entre os mais conhecidos, entre fins dos anos 1960 e anos 1970, vê-se consolidar dois tipos de estudos sobre a África. Uns de maior fôlego, preocupados em reconstruir a história africana, desde uma perspectiva estrutural de longo prazo. Em uma lista discutível, pode-se citar, por exemplo, neste caso, os estudos de Joseph Ki-Zerbo, Históia da África Nega (1979); Basil Davidson, A Áfica ma Históia (1975) e A velha África reesecobeta (1977); Daniel Mc Call, A Áfica empespetiva terporal (1964); Endre Sik, A Históia da Áfica Nega (1976). Por outro lado, têm-se outros trabalhos que tem por objeto de estudo temas modernos e contemporâneos, relacionados ao tráfico escravista, colonialismo e descolonização, como os ensaios do próprio Basil Davidson, por exemplo, A libataçãoda Guiné aspetos deuma revdựãoaficana (1975); Terence Ranger, Revdtas na Rodésia do Sul: um estudb da eistênia africana (1967); Walter Rodney, Conm a Europa subdesenviveua Áfica (1972) e A Históna da Costa da Guiné(1970); Boubacar Barry, O Reino doWallo(1970); Philip Curtin, O traficoescavista noAttântico(1970) e Trocas comeriais na Áfica Précdonial (1975); Henri Brunschwig, Partilha da Áfinca nega (1971); Samir Amin, O desenduimeto designal: ensaio sdre as formaỹás scaiais do capitalismo peiféico (1975); e muitos outros autores e textos.

Em 1980, com a participação de intelectuais africanos e estrangeiros, a UNESCO iniciou a publicação da Históia Geral da Áfica um ponto de virada nos estudos sobre a histónia africana. Planejado desde 1966, a partir de um pedido formal dos países africanos recém-libertados, os oitos volumes da Históia Geal da Áficica tornar-se-iam fonte obrigatória sobre 0 assunto, en que os maiores especialistas da área puderam, democraticamente, expor seus pontos de vista sobre o passado e o presente africano. 
Como observa Henk Wesseling (1992: 111), o que se constata a observar esta historiografia crescente sobre a África, é que, por suas características próprias sobretudo pelo fato de suas fontes escritas serem em sua maioria exógenas, a História da África tende a seguir em muito as características atribuídas a Escola dos Annales e a novdlehistare uma histónia inter-disciplinar, problematizada e totalizante. Afinal, para reconstruir o passado africano era preciso apreender a reconstruir o passado de outras formas. E, estas formas, não se restringiam à África.

A partir dos anos 1980 e 1990, com a ampliação ainda maior deste campo de estudos, vê-se uma multiplicação de estudiosos, temas e métodos de trabalho que tomará 0 estudo da História da África uma área de disciplinar consolidada e internacionalmente reconhecida. Nestes, entretanto, o enfoque toma-se cada vez mais regionalizado, tratando de regiões especificas da África: Austral, O cidental, Saheliana, etc. Trata-se de um avanço tanto intelectual, quanto institucional, como a formação de novas áreas de estudos historiográficos africanos dentro e fora deste continente.

Nesta ampliação, vêse surgir novos especialistas da temática, que se tornaram figuras importantes no meio acadêmico. Isto, tanto fora da África, como J. Vansina, J. Thornton, C. Coquery-Vidrovitch, P. Lovejoy, J. Miller, Y. Kopytoff, A. Costa e Silva, K. Asante, M. Bernal, C. Lopes, D. Birmingham, e outros; quanto dentro da África, como B. Barry, A. F. Ajahi, A. Boahen, B. A. O got, V. Mudimbe', I. A. Akinjogbin, T. Falola, M. Diouf, E. J. Alagoa, e outros.

Concomitantemente, com a difusão da internet e das políticas de reconhecimento dos movimentos negros ao redor do mundo, vários assuntos relacionadas à temática africana e afro-descendente, tomam-se conhecidos fora do campo acadêmico. Este é o caso, por exemplo, do saber hoje disseminado sobre temas que antes eram restritos a comunidade acadêmica, como 0 afro-centrismo, escravidão, diáspora, egiptologia, cultura negra, etc. Nem sempre, obviamente, com o devido rigor científico. Seja como for, afinal, a Á frica e a diáspora são hoje tidas como fonte de conhecimento para a humanidade.

\section{Eurocentrismo e historiografia africana}

9 Embora seja filósofo de formação, V. Y. Mudimbe tem algumas obras de referência no campo historiográfico de África; em especial: A invenãa da Áfica (1988). Não por acaso, assim como M. Foucault, sua prática filosófica está muito próxima ao trabalho historiográfico. 
A difusão de uma História mais crítica, no século XX, e o surgimento da História disciplinar nos países do "Tereiro Mundo" alteraram, sem dúida, o quadro marcadamente eurocêntrico do pensamento social anterior.

No que tange ao saber sobre a África, este avanço da historiografia é inegável. Entretanto, após duas gerações de historiadores formados no tema, desde a 2ํㅡㅁ Grande Guerra, a crítica ao eurocentismo segue sendo uma questão central para os autores contemporâneos que tratam do assunto.

Neste sentido, parte do trabatho de autores atuais como Thomton, Lovejoy e Vansina, provém do questionamento de supostos pressupostos da herança crítica anterior, da primeira geração da historiografia sobre a África, tidos como igualmente reprodutores de uma visão de mundo eurocêntrica, tal qual a historiografia colonialista. Vansina (1994), por exemplo, questionou os afp-centristas por não desmistificarem 0 mito da excepcionalidade grega, em vez de procurarem as origens africanas desta. Thornton (2004) se refere ao suposto eurocentrismo contido nas obras que trabalham com a teoria do sistema-mundial de Immanuel Wallerstein; visto que, ali, a Europa continuaria surgindo como o único sujeito histórico da modemidade.

De um modo geral, pode-se observar, nestes e outros autores contemporâneos, assim como em filósofos africanos atuais, como Appiah e Mudimbe, uma tendência a compreender os males africanos voltando suas críticas às póprias elites daquele continente. Tratase de uma caracterização que se coloca, na visão destes, como oposta àquela de gerações anteriores, pois, estas, supostamente, estariam se entendendo os males africanos como epifenômeno da dominação européia-ocidental. Fosse ela representada pelo tráfico escravista, pela Era Colonial, pelo Imperialismo ou pelo Neo-colonialismo.

Como aponta John Iliffe (1995: 1), esta visão crítica dos hitoriadores contemporâneos de África às gerações anteriores é, grosso modo, um sintoma da crise moral advinda da derrocada dos Estados africanos, após as independências nacionais. Findo o colonialismo, os problemas nacionais de tais países passam a ser vistos mais como algo interno do que externo. Neste contexto, a crítica ao eurocentrismo ressurge como uma auto-crítica, desvelando uma culpabilidade dos próprios africanos, em particular, de suas elites, em relação aos problemas históricos do continente $^{10}$.

Neste sentido, a História da África reconstrói sua relevância teórica e política, estabelecendo seu local de contribuição às diversas correntes interessadas na superação da

10 Tal fato não se circunscreve a África pós-independente. Em relação à Índia, por exemplo, o historiador Ranajit Guha (1997) diz explicitamente que o nascimento da "historiográfica pós-colonial" naquele país, defendida pelo grupo intelectual do qual faz parte (Grupo dos Estudos Subalternos da Ásia do Sul) foi uma consequêencia teórica do "fracasso" dos projetos de modernização nacional. 
agenda eurocêntrica das ciências sociais. Como observa Edgardo Lander (2000: 9), trata-se, hoje, de um movimento amplo e transdisciplinar nas ciências humanas, que visa desconstruir a tradição eurocêntrica em um ponto central: na literatura auto-legitimadora da "modemidade ocidental".

Buscando qualificar tais críticas contemporâneas ao eurocentrismo, Walter Mignolo (2003: 76) assinala algo pertinente a este ensaio. Diz o autor que, para além da sua aparente heterogeneidade, existiria uma essência comum a tais críticas, a saber, suas tentativas de construir visões renovadoras das ciências humanas, desde um viés pós-eurocentrico. Para 0 autor, esta seria uma premissa necessária para o desvelamento dos saberes subalternizados pela "diferença colonial". Em outros termos, dos saberes dos povos submetidos à expansão dos colonialismos internos e externos, engendrados pela ocidentalização do mundo.

Desde este olhar, há de se repensar na historiografia sobre a África, as alternativas teórico-metodológicas criadas pelos historiadores para tentar construir uma História científica em relação ao seu objeto de estudo ${ }^{11}$.

Várias são as possibilidades interpretativas para delinear essa contribuição dos estudos históricos sobre África para o conhecimento universal. Aqui, estabelecer-se-á uma divisão temporal, que se pressupõem como frutífera em relação à temática levantada. Assim, se trata dos estudos históricos em duas grandes épocas: Antiga (surgimento do Homo sapiens até século V d.c.) e Moderna/ Contemporânea (século V d.c. aos dias atuais).

Entre os estudos da África Antiga podem-se destacar aqueles que visam uma abordagem de longa duração, buscando desenvolver uma escrita da História de caráter milenar, como os de Basil Davidson (1959; 1975; 1977), Robert Corvenier (1960), Pierre Bertaux (1966), R. Oliver e J. Fage (1962), Jean-Suret Canale (1961), John Reader (1997), John Iliffe (1995), Joseph Ki-Zerbo (1979), Daniel Mc Call (1964), Endre Sik (1976), Roland Oliver (1994), etc.

Nestes estudos, se destacam dois tipos de contribuição a uma visão mais ampliada da História. Em primeiro lugar, tem-se a utilização das ciências naturais ("exatas" e "biológicas") como instrumental de pesquisa historiográfica. Os casos exemplares se referem à utilização do conhecimento arqueológico e paleontológico. Da Arqueologia, veio a utilização do método de carbono 14, que marcou uma reviravolta na datação dos

11 Outra tendência contemporânea é negar, como eurocêntrica, a própria idéia de cientificidade, engendrada pelo trabalho historiográfico. Esta não é a intenção deste ensaio, embora reconheçamos a pertinência desta discussão, cujas origens remontam, pelo menos, ao século XIX. 
artefatos e na cronologia humana no continente. Tornou-se, por isso, referência obrigatória de pesquisa aos africanistas, desde a década de 1950. Ademais, a análise dos sítios arqueológicos, com métodos daquela disciplina, foram fartamente utilizados na História, 0 que implicou em novos problemæ interpretativos aos historiadores. Da paleontologia vieram saberes importantes para estudar o processo de hominização do Homem. Assim, as datações históricas foram ampliadas à escala milenar, com a utilização de métodos como 0 do isótopo potássio-argônico (O benga, 1980: 92).

As ciências naturais "exatas" se fizeram presentes, também, nas análises demográficas e geomorfológicas sobre o Homem no continente fricano. Além de contribuir com a construção de uma História Econômica da África, em tempos Pré Coloniais, a matematização permitiu o estudo das relações entre o Homem e o Meio Natural em áreas diversificadas, em especial, na climatologia (Obenga, 1980: 93s). Tais ensaios têm influenciado outros, como os de John Illiffe (1995), que enfatizam uma perspectiva geo-histórica de longa duração, mostrando a capacidade dos povos africanos em transformar e, quando necessário, se adequar às condições geográficas.

Do mesmo modo, as ciências naturais tomaram-se cada vez mais importantes em ramos particulares, como a paleobotânica e a parasitologia, que se consolidam como saberes essenciais à História da África. Tais conhecimentos permitem que o estudo da alimentação e da fauna africana, assim como das doenças e epidemias, saia do plano leigo. Ademais, a genética contemporânea, a partir da análise mitocondrial, solidificou o saber sobre a genealogia humana, atestando, por exemplo, a origem africana do Homem.

Também visando um saber interdisciplinar, os estudos sobre a África moderna e contemporânea, conquistaram, pelo menos, outros dois méritos visíveis.

O primeiro deles foi a utilizæ̧ão da Linguística e da históia oral como instrumentais fundamentais para o conhecimento histórico. A relação entre História da África e Lingüística é antiga. Foi ela, por exemplo, que possibilitou vários procedimentos de identificação étnica das populações africanas, desde o século XIX. Nos últimos decênios, entretanto, tal aproximação tem outra importância. Ela possibilitou que 0 conhecimento sobre a história não ficasse restrito aos que os outros povos árabes e europeus escreveram sobre os africanos. Isto é essencial num passado em que, salve exceções como o Egito antigo e seus arredores, e algumas áreas romanizadas do Norte da África, os africanos não deixaram registros escritos de sua cultura e visão de mundo. Tal foi o intento que moveu autores como Jean Vansina (1958), Djibril T. Niane (1960), Joseph 
Ki-Zerbo (1969), David Cohen (1972), Amadou Hampaté Bâ (1972), Joseph Miller (1980), E. Alagoa (1968; 1973), entre outros, a formular métodos de investigação e interpretação histórica em que a história oral fosse um principio primordial de análise cientifica do continente.

O segundo mérito dos estudos sobre a África moderna foi o de terem mostrado, de modo mais plural e amplo, em seus trabalhos, o africano como sujeito da sua própria histónia. Em especial, em sua face mais visível, na ação política. Aqui, obviamente, eles tiveram grandes inspiradores e polemistas, como Frantz Fanon e Cheikh Anta Diop. Todavia, em relação à interpretação histórica, 0 acúmulo de ensaios sobre a história modema e contemporânea da África tem possibilitado uma visão mais complexa da atuação dos africanos na constituição e reprodução de suas sociedades. Os africanos de hoje e outrora se tornam, gradativamente, mais pluridimensionais. Em uma palavra, mais humanos; feliz e infelizmente...

Neste particular, é visível como os estudos históricos contemporâneos tendem a desmistificar o caráter ahistórico atribuído aos africanos por pensadores mais eurocêntricos e, por conseguinte, mais racistas. 0 africano aparece, assim, com uma presença mais viva na histónia humana.

Estas e outras tendências recentes da historiografia sobre a África têm sido um ataque considerável ao eurocentrismo na História disciplinar. É perceptível, sobretudo, que o esforço por uma história interdisciplinar, nesta área do conhecimento, tem permitido uma reconstrução histórica mais complexa, em que a utilização cruzada de fontes se tomou uma premissa metodológica. Tal fato tornou-se uma condição necessária para uma história menos eurocêntrica em relação à África; e, como colocou Ki-Zerbo (1980: 377), uma premissa para a concretização de um projeto transdisciplinar do conhecimento, ainda a ser construído.

Por outro lado, a continuidade de uma perspectiva que visou descolonizar a História da África, em um âmbito mais geral, reforçou um viés de interpretação heurística deveras interessante. Assim, os conceitos de trabalho historiográfico parecem cada vez mais imanentes à própria história, em vez de basearem em categorias fechadas, construídas a posteriori. Tal tendência tem aproximado, cada vez mais, a História da Antropologia. Aí, a novidade tem sido a difusão de uma "antropologização" dos conceitos historiográficos, que postula uma visão crítico-assimilativa acerca das categorias clássicas de entendimento dos fatos sociais. Neste sentido, por exemplo, desde uma perspectiva africana, autores como Akinjogbin et al. (1981), vêm postulando uma ressignificação conceitual de categorias 
como poder e território, que passam a ser estabelecidas segundo seu sentido cultural nativo: akan, ibo, etc. Joseph Ki-Zerbo e Boubou Hama (1980), no mesmo sentido, reclamam pela compreensão singular de história e fazer histórico das próprias sociedades africanas. Um intento próximo pode ser rastreado em Juret Suret-Canale (1974), Samir Amin (1976), E. Idowu (1980), etc; assim com em outros autores, menos preocupados com o padrão historiográfico, como Leopold Sédar Senghor (1964), O kot p’Bitek (1971) e Haris MemelFoté (1970). Tal empreendimento tende a formar uma História da África cada vez mais particularizada e especializada, pelo menos na África.

Apesar da perspectiva otimista que tais avanços trazem para a História da África é difícil crer, eles implicariam, por si, a superação da agenda eurocêntrica da História e do campo acadêmico. Isto porque, como ciência do espírito, os desenvolvimentos teóricometodológicos na História não implicam, necessariamente, avanços paradigmáticos.

Para caminhar nesta direção, haveria que se aliar disposição científica e política. Esta estaria voltada para a fundamentação de um saber que hoje se chama multicultural, em que a racionalidade humana é culturalmente contextualizada. Compreender a historicidade e a contemporaneidade desta proposta é tarefa de uma História não disciplinada.

\section{Bibliografia}

ALAG OA, E. J. The use of oral literacy data for history. JAF, 81 (7), 1968. . O ral tradition and archaeology: the case of Onyoma. OM, 1 (1), 1973.

ĀKINJŌ GBIN I. A. et al. Coneqtodd podrenAfica Barcelona: Serbal, 1981.

AMIN, Samir. Eurocentrisma oútica deumaidkedoja Lisboa: Dinossauro, 1994.

. O desenvivimento desigual: ensaio sdre as formaçães saiais do capitalismo periférica Rio de Janeiro: Forense-Universitária, 1975.

APPIAH, K wame. Na casa de mau pai: a África ma filosofia da altura. Rio de Janeiro: Contraponto, 1997.

BÂ, Amadou H. Aspects de la civilizacion africaine. Paris. PreséneAfricaine(8), 1972. . A tradição viva. In: KI-ZERBO, J. (coord.). Meoobloga epréhistóna da África São Paulo: Ática; Panis: UNESCO , 1982.

BARBOSA, Wilson N. Cultura nega e daminaçãa Coleção Aldus, no. 9. São Leopoldo, RS, Brasil: Editora UNISINOS, 2002.

BARRY, Boubacar. Senegâmbia: o desafio da Históia Rejjonal. Rio de Janeiro: SEPHIS/ CEAA (UCAM), 2000.

BERTAUX, Pierre. Áfica: desdelaprehistoria hasta los estadosactuales Mexico: G abriel Mancera, 1972.

BURKE, Peter. A Redư̧ão Framesa da histarografia: a Escda dos Anmales (1929-1989). São Paulo: UNESP, 1991.

CO HEN, David. Thehistorical tradion of Busoga, Mukama and Kintu London: Oxford/ The Claredon Press, 1972.

CO RO NIL, Fernando. Mas allá del occidentalismo: hacia categorías históricas no imperiales. Casa delas Améicas Havana, no 206, janeiro-março. 1999. 
CURTIN, Philip. Tendências recentes das pesquisas históricas africanas. In: KI-ZERBO, J. (coord.). Metoddoga epréhistóia da Áfinca São Paulo: Ática; Paris: UNE SCO , 1982.

DIOP, Cheikh A. A origem dos egípcios. In: MOKHTAR, G. Históna geral da Áfica: a África antiga São Paulo: Ática/ UNESCO, 1980.

$197 \overline{3}$

. Theafican orign of aivilization mthor reality. New Y ork, Lawrence Hill \& Company,

DUSSE L, Enrique. 1492: oendarimetodbatra Petrópolis, RJ: Vozes, 1993.

ED GAR, Andrew \& SEDG WICK, Peter. Teeria altural deA a Z: conceitos have para entender o mundo contemparânea São Paulo: Contexto, 2003.

EZE, Emmanuel C. El color de la razon: las ideias de "raza" em la antropologia de Kant. In: MIGNOLO, W. (comp.). Capitalismo e geopdítica de conoimienta d arocentrismo y la filosofia de la libetacón end dbateintdetual contemparánea Buenos Aires: Signo, 2001, pp. 201-252.

FAGE, D . J. (ed.). African discovers her past. London: Oxford University Press, 1970.

. A evolução da historiografia da África. In: KI-ZERBO, J. (coord.). Matodogja e préhistóna dâAfíca São Paulo: Ática; Paris: UNE SCO , 1982.

FANON, Frantz. Os condanados da Tera Juiz de Fora, MG: Ed. UFJF, 2005.

FARIAS, P. F. de Mores. Afrocentrismo: entre uma contranarrativa histórica universalista e 0 relativismo cultural. AfroÁsia, 29;30. Salvador, BH, 2003, pp. 317-343.

FIERMAN, Steven. Dissolution of World History. In: BATES, R. \& MUDIMBE, V. Y., O 'BARR, J. (eds.). Á frica and the dsaiplines: terecontributions of rearchin África to the Social Sciences and Humanites Chicago: University of Chicago Press, 1993, pp. 167-212.

FO NTANA. Históia: análisedopassadbeprgitosaial. Bauru: ED USC, 1998

FO UREZ, G erard. A construção das dênias introduçãoafiloscfia ea éica das dênias São Paulo: UNESP, 1995.

ID O WU, E.B. African Traditional Reigion a definition London: S.C.M Press, 1980.

ILIFFE, John. Africans: thehistaryofa continent. New Y ork: Cambridge University Press, 1995.

GUHA, Ranajit \& SPIVAK, G ayatri (eds.). A subaltemstudiesreader(1986-1995). Minneapolis (USA): Minnesota University, 1997.

KI-ZERBO , Joseph. Da natureza bruta à natureza libertada. In: K I-ZERBO , J. (coord.). Metoddoga epréhisónia daÁfrica São Paulo: Ática; Paris: UNESCO , 1982.

. Os métodos interdisciplinares utilizados nesta obra. In: KI-ZERBO, J. (coord.). Méơdog̣a epréhisóniada África São Paulo: Ática; Paris: UNE SCO , 1982.

\& HAMA, Boubou. Lugar da história na sociedade africana. In: KI-ZERBO , J. (coord.). Méōodöga epréhistóia da Áfinca São Paulo: Ática; Paris: UNE SCO, 1982.

LANDER, Edgardo (coord.). La donialidad de saber. emrentrismo y denias soiales Buenos Aires: CLACSO, 2000.

MCCALL, D aniel F. Africa in timeperspetive a dsassion of historial reconstrurtion fromunnitten sarces Boston: Boston University Press, 1964.

MEMEL-FOTÉ, H. L 'idée du monde dans lês cultures negro-africaines. PréseneAfricaine Paris, no. 73, 1970.

MIGNO LO, Walter. Históias locais, projeos gdbais: cdarialidade, saberes subaltemos epensamento liminar. Belo Horizonte: UFMG , 2003.

MILLER, Joseph. Theafican past speaks Folkestone and Hamden: D awson and Archon, 1980.

OBENGA, T. Fontes e técnicas específicas da história da África: panorama geral. In: KI-ZERBO, J. (coord.). Međodoga epréhistóia da Áfica São Paulo: Ática; Paris: UNESCO, 1982.

OLIVA, Anderson R. A história da África em perspectiva. Reista Múltipla Brasília, 10(16): 9- 40, jun., 2004.

OLIVER, Roland. A expeiênia afiicana: da préhistaia aos dias atuais. Rio de Janeiro: Jorge Zahar, 1994.

ORTIZ, Renato. Umatrotenitónia ensaiossdbrea mumializaçãa São Paulo: Olho d’Água, 2000 
P'BITEK, O kot. African reigiansinWestem Sdhdarship Nairobi: Kenyan Literature Bureau, 1971.

QUIJANO, Anibal. Colonialidad del poder, eurocentrismo y America Latina. In: LANDER, Edgardo (coord.). La clanialidad dd saber: enroentrism y denaas soiales Buenos Aires: CLACSO, 2000, pp. 201-46.

READER, John. Africa: abiogaphyofthecontinent. London: Hamish Hamilton, 1997.

SAID , Edward. Orietalisma ocientecomoinverşãodbcidante São Paulo: Companhia das Letras, 1990.

SENGHO R, Léopold S. Négitudeđ humanisme Paris: Editions du Seuil, 1964.

SHOHAT, E. \& STAM, R. Unthinkingeurcentrism miltialturalismand themedia. London : Routledge, 1997.

SILVA, A. C. Os esturbs deHistória daÁfrica esua impatânia para o Brasil In: A dimensão atlântica da África. II Reunião Internacional de História da África. Rio de Janeiro, CEA-USP/SDGMarinha/ CAPES, 1996, pp. 13-20.

SO UZA, Maria G. Ilustração e Históia: o pensamento sobrea Históia no lluminismo francês São Paulo: Discurso Editorial/ FAPESP, 2001.

SURET-CANALE, Juret. As sociedades tradicionais na África tropical e o conceito de modo de produção asiático. In: C.E.R.M. O modbdeproduçãoasática Lisboa: Seara Nova, 1974.

THORNTON, John. A África eos aficicanos na fơmasãodomundoA tlântico(1400-1800). Rio de Janeiro: Elsevier, 2004.

VANSINA, Jan. A tradição oral e sua metodologia. In: KI-ZERBO, J. (coord.). Međddoga epré hisóniadaÁfrica São Paulo: Ática; Paris: UNE SCO , 1982. . LivingvithÁfrica. Madison: The University of Wisconsin Press, 1994.

YO UNG, Robert. Whitemythdojes writinghistayand theWest. London; New Y ork: Routledge, 1990.

WALLERSTEIN, Immanuel. O univesalismoearcpear a retóica dbpodk. São Paulo: Boitempo, 2007. et al. Para abniras dêniassaiais São Paulo: Cortez, 1996.

WESSELING, Henk. História de além-mar. In: BURKE, P. (org.). A escrita da Históia: nowas pespetivas São Paulo: UNESP, 1992. 